\title{
Un Dios con entrañas de misericordia que escucha el clamor de su pueblo (II)
}

\section{Rafael de Sivatte, Centro de Reflexión Teológica, San Salvador.}

\section{Los tiempos del exilio (550 a. C.)}

Para el tema de este artículo - la misericordia de Dios hacia su pueblo-, el tiempo del exilio es de especial importancia. Israel se ha quedado sin signos de identificación: sin Jerusalén, sin el templo, sin el sacerdocio. Peor aún, ha caído en manos de los enemigos, ha perdido toda esperanza. En tal situación, el pueblo se hace grandes y graves preguntas sobre Dios y sobre su relación con él. Son preguntas que muestran una gran desesperanza y se pueden formular de esta manera, ¿tiene poder nuestro Dios sobre los dioses de nuestros enemigos?, ¿nos sigue amando?, ¿nos podemos seguir relacionando con él sin tener espacios ni tiempos sagrados?, ¿tenemos aún alguna tarea testimonial en medio de las naciones?, ¿podemos mantener nuestra esperanza?

Existen algunos textos que muesiran el dramatismo y la desesperanza de estas preguntas $y$, aparentemente, afirman que Dios ya no es compasivo ni tiene piedad. Así, por ejemplo, Lamentaciones 2, 2.17.21; 3, 43; 4,16:

El Señor ha destruido sin piedad todas las moradas de Jacob; ha derruido en su furor las fortalezas de la hija de Judá; por tierra ha echado, ha profanado al reino y a sus príncipes... Yahveh ha hecho lo que había resuelto, ha cumplido su palabra que había empeñado desde antiguo; ha destruido sin piedad; ha hecho alegrarse sobre ti al enemigo, ha exaltado la frente de tus adversarios... Por tierra yacen en las calles niños y ancianos; mis vírgenes y mis jóvenes cayeron a cuchillo; thas matado en el día de tu cólera, has inmolado sin piedad!... Te has envuelto en cólera y nos has perseguido, has matado sin piedad... El rostro de Yahveh los dispersó, no volverá a mirarlos. No hubo respeto para los sacerdotes, ni piedad para los ancianos... 
Parece, pues, que Yahveh ya no tiene piedad, y eso es lo que produce la ruina y la desesperanza del pueblo. En medio del dramatismo, sin embargo, de estas lamentaciones encontramos también la convicción de que "aún está vivo el amor de Yahveh y su piedad no se agota" (Lam 3, 22). "El hace sufrir, pero también se compadece por su gran amor" (Lam 3, 32).

Esta confianza última, de tono trágico, pudiéramos decir, aparece también en las tres grandes obras que se acababan de redactar en el exilio: segunda edición de la obra deuteronomista, la obra sacerdotal y el segundo Isaías. En la presentación de los grandes personajes de Israel (Jacob, Moisés, David, Salomón...) aparece, en medio de graves preguntas que se vive la seguridad en un Dios que se mantiene fiel. Veámoslo.

\subsection{Obra deuteronomista (segunda edición)}

En la reelaboración de la obra deuteronomista, Moisés anuncia al pueblo que si se convierte de su infidelidad, "Dios renovará tu vida y tendrá misericordia de ti. Te volverá a reunir de entre todos los pueblos donde te había dispersado" (D1 30, 3).

La misma idea aparece con frecuencia en el segundo libro de Samuel. David pide a Yahveh que sea misericordioso y fiel con aquellos que han sido misericordiosos con Saúl y lo han sepultado respetuosamente (2Sam 2, 5-6). Dios se compromete a no apartar de David su amor, como lo hizo con Saúl (2Sam 7, 15). David, cuando su hijo está a punto de morir, ora a Dios para que tenga compasión y lo mantenga con vida (2Sam 12, 22). El mismo David, que se reconoce como pecador, prefiere caer en manos de Yahveh, "que es muy misericordioso", que en las de los seres humanos (2Sam 24, 14). Por último, al final de su vida David confiesa que "él da grandes victorias a su rey, muestra el amor que tiene a su ungido, a David y a su linaje por siempre" (2Sam 22, 51).

La misma idea recorre el primer libro de los Reyes, refiriéndose a Salomón. Cuando Dios ofrece a Salomón que le pida lo que desea, éste comienza su oración -para que Dios le siga mostrando su favor y siga amando al pueblo en el exilio- de esta manera:

Tú demostraste un gran amor a tu siervo, mi padre David, que se comporlaba ante ti con fidelidad, bondad y reclitud de corazón. Tú le mantuviste tu gran amor dándole un hijo que le sucediese en el trono, como ocume hoy $(1 \operatorname{Re} 3,6)$.

En la gran oración de dedicación del templo, Salomón pone en palabra la realidad del pueblo en el exilio y dice:

Señor, Dios de Israel, no hay Dios como tú en el cielo y en la tierra. Tú mantienes la alianza y la fidelidad hacia tus siervos que se comportan con un corazón sincero...Tú, Señor mi Dios, presta atención a la plegaria y a la súplica de este siervo tuyo, escucha el clamor y la plegaria que este siervo Digitalizado por Biblioteca "P. Florentino Idoate, S.J."

Universidad Centroamericana José Simeón Cañas 
tuyo te dirige hoy... Perdona a tu pueblo que había pecado contra ti, perdona todas sus infidelidades y haz que se compadezcan de ellos los que les hagan cautivos... Ten los ojos abiertos, escucha las súplicas de este siervo tuyo y las de tu pueblo siempre que clamen a ti $(1 \operatorname{Re} 8,23.28 .50 .52)$.

Salomón, pues, mantiene el presupuesto de que Dios es fiel hacia los que obran con corazón sincero, y le pide por el pueblo, incluso cuando éste es rebelde, para que escuche su clamor, lo perdone y haga que sus deportadores tengan compasión de él. Esta actilud de Salomón llega a impactar a la reina de Saba. Admirada por la sabiduría de Salomón, bendice a su Dios porque lo ha instituido como rey para siempre, "porque se ha complacido en él... por el amor eterno que Yahveh tiene a Israel le ha hecho rey para que gobieme según el derecho y la justicia" (1Re 10,9). Nuevamente es el amor de Dios el que produce bendición.

Por último, el segundo libro de los Reyes, escrito también en el contexto del exilio, reflexiona sobre la opresión que el rey de los arameos ejerce sobre los israelitas y recuerda cómo "el Señor se compadeció y tuvo misericordia de ellos. Se inclinó a su favor y por su alianza con Abraham, Isaac y Jacob no les quiso exterminar..." (2Re 13, 23). Y es también el amor de Dios hacia su siervo David el que lo mueve a salvar a Ezequías de la muerte y el que socorre a la ciudad ante sus enemigos $(2 \operatorname{Re} 20,6)$. La compasión y la misericordia de Dios hacen que Yahveh se incline en favor de su pueblo y se ponga a su lado.

En resumen, la segunda edición de la obra deuteronomista, revisada en el tiempo del exilio, vuelve a subrayar el hecho fundamental de que Dios se deja llevar por su amor y su misericordia.

\subsection{La obra sacerdotal}

También el movimiento sacerdotal $(P)$ insiste en dar respuesta a las graves preguntas del exilio, y con esa intención revisa las historias de los orígenes, de los antepasados y del éxodo. Así, por ejemplo, Jacob pide a Dios que sus hijos encuentren misericordia ante José, el ministro del faraón (Gen 43, 14). En realidad, el texto está haciendo alusión también a los judios exiliados y a los ministros babilonios.

En un texto del Exodo, cuando Moisés pide que Dios pase ante él, Dios le contesta: "Yo haré pasar ante tu vista toda mi bondad y pronunciaré delante de ti el nombre de Yahveh" (Ex 33, 19), con lo cual está queriendo decir que se le manifestará tal como es. A continuación, Yahveh pasa ante él, y, tal como le había prometido, le manifiesta su modo de ser y actuar, y especialmente su misericordia, lo cual es una confirmación del pueblo en el exilio. Así habla Dios: 
Yahveh, Yahveh, Dios compasivo y benigno, lento para castigar, fiel en el amar. Mantengo mi amor hasta mil generaciones, perdono las culpas, las faltas $y$ los pecados, pero no tengo al culpable como inocente. (Ex 34, 6-7).

La reacción de Moisés no se hace esperar y su respuesta, en forma de oración, que se espera que sea la misma que tenga el pueblo en el exilio, se basa en la convicción y confianza de que Dios, actuando según su modo de ser, perdonará las culpas y los pecados de su heredad (cfr. Ex 34, 19). Esta relación con Dios es la que da esperanza de que también en el tiempo del exilio, Dios actuará con misericordia y se manifestará siempre como quien es bondadoso.

\section{El segundo Isaías}

Por lo que loca al tema de nuestro estudio, en el segundo Isaías - la misericordia de Dios- lo podemos dividir en los siguientes cuatro grandes apartados.

\section{a) Dios, aparentemente, ha abandonado a su pueblo en el exilio}

La explicación que da el segundo Isaías a la realidad del exilio es la indignación de Dios por las infidelidades de su pueblo. Pero, a pesar de las apariencias, lo que queda claro, en definitiva, en estos textos es que Dios no quiere, de ningún modo, la desı́rucción de su pueblo, sino que mantiene su amor hacia él. Incluso en los textos en que Isaías muestra a un Dios indignado, que ha abandonado al pueblo, siempre acaba diciendo que — de hecho- no lo quiere abandonar: "Irritado estaba yo contra mi pueblo, había profanado mi heredad y en tus manos (se refiere a Babilonia) los había entregado; pero tú no tuviste piedad de ellos; hiciste caer pesadamente tu yugo sobre el anciano" (Is 47,6 ). La indignación de Dios, Señor de la historia, se sirve de Babilonia, pero no para destruir al pueblo, sino para corregirlo y para que se convierta. Babilonia no lo hizo así, sino que actuó de manera muy violenta contra el pueblo de Israel con la intención de destruirlo, y por esto Dios, finalmente, se indignó contra Babilonia, que había ido más allá de la tarea encomendada.

En otros textos se vuelve a insistir en la razón del exilio y la limitación del tiempo del "castigo". "En mi cólera te herí pero en mi benevolencia he tenido compasión de $t i "(I s 60,10)$. Y en otro texto dice:

Por un breve instante te abandoné, pero con gran compasión te recogeré. En un arranque de furor te oculté mi rostro por un instante, pero con amor eterno te he compadecido... he jurado que no me irritaré más contra ti ni te amenazaré. Pues, aunque los montes se corran y las colinas se muevan, $m i$ amor no se apartará de tu lado y mi alianza de paz no se moverá. Te lo digo yo Yahveh, el que re quiere (Is 54, 7-10). 
En otros textos -en medio de su censura- Dios muestra su amor: "Pues bien, soy yo, soy yo quien te borra las faltas por amor a $\mathrm{ml}$ mismo. Ya no recordaré tus pecados" (Is 43, 25). "Pero yo, por amor de mi nombrel, he sido paciente, por $m i$ gloria me he contenido y no he querido destruirte" (Is 43, 25). Por tanto, es el anor de Dios a lo que es suyo lo que hace que Dios no destruya y salve.

\section{b) El profeta invita al pueblo de parte de Dios a dejar de hacer el mal}

Dios, entonces, invila al pueblo a cumplir su voluntad, porque está dispuesto a pactar una alianza para siempre, de acuerdo a las promesas amorosas y fieles y a hacer de su pueblo un pueblo que convoque a lodos los pueblos por el amor de Dios. El profeta exige, sin embargo, que los malvados dejen su maldad, con la certeza de que Dios tendrá compasión y los perdonará.

Apliquen el oído y acudan a mí, oigan y vivirá su alma. Pues voy a firmar con ustedes una alianza etema: las amorosas y fieles promesas hechas a David. Mira que por testigo de las naciones te he puesto, caudillo $y$ legislador de las naciones. Mira que a un pueblo que no conocías has de convocar, y un pueblo que no te conocía, a ti conerá por amor de Yahveh tu Dios y por el Santo de Israel, porque te ha honrado2. Busquen a Yahveh mientras se deja encontrar, llámenle mientras está cercano. Deje el malo su camino, el hombre inicuo sus pensamientos, y vuélvase a Yahveh, que tendrá compasión de él, a nuestro Dios, que será grande en perdonar (Is 55, 3-7).

\section{c) Anuncio de un futuro movido por la compasión de Dios}

Una serie de textos se centran, más bien, en la presentación de un futuro movido por la compasión de Dios. Dice Yahveh que "habrá un camino real para el resto de su pueblo... como lo hubo para Israel, cuando subió del país de Egipto3. Y dirás aquel día: Yo te alabo, Yahveh, pues aunque te airaste contra mí se ha calmado tu ira y me has compadecido" (Is 11, 16 y 12, 1). La compasión de Dios es, pues, lo que producirá el cambio de la situación. También hay otros textos:

1. Es conveniente explicar qué significa la expresión "Dios salva a su pueblo por su nombre, por su gloria", ya que puede dar la impresión de un cierto egoísmo en Dios. Para superar esa impresión es importante tener en cuenta la concepción de que la gloria y el nombre de Dios están en juego cuando la realidad del ser humano es de pecado, de inhumanidad, de no vida. Decir, por tanlo, que "Dios acluará por amor a su nombre" es lo mismo que decir que Dios acluará por amor a la vida del ser humano.

2. Es decir, Israel volverá a tener el papel de siempre, el de dar tal testimonio que las naciones lleguen a conocer a su Dios y sobre todo su estilo de actuar.

3. Isaías presenta el camino nuevo desde el exilio hacia la tierra prometida como una nueva liberación para el pueblo. Este será liberado de la misma manera que lo fue de Egipto y seguirá un camino hacia la tierra, parecido al que siguieron sus antepasados al salir de Egipto. 
Pronto llegará la hora de Babilonia, sus días están contados. El Señor se compadecerá de los descendientes de Jacob. Los israelitas serán aún sus preferidos; les hará regresar a su tierra y los extranjeros se unirán a ellos (Is $13,22$ y 14,1$)$.

En la misma línea habla lsaías $30,18-19 ; 49,10.13 .15 ; 61,11 ; 62,1$. Veamos los textos:

Sin embargo aguardará Yahveh para hacerles gracia, y así se levantará para compadecerles, porque Dios de justicia4 es Yahveh: no llorarás ya más; de cierto tendrá piedad de ti, cuando oiga tu clamor; en cuanto lo oyere, te responderá... No lendrán hambre ni sed, ni les dará el bochorno ni el sol, pues el que tiene piedad de ellos los conducirá, y a manantiales de agua los guiará... ¡Aclamen, cielos, y exulta, tierta!... pues Yahveh ha consolado a su pueblo, y de sus pobres se ha compadecido... ¿Acaso olvida una mujer a su niño de pecho, sin compadecerse del hijo de sus entrañas? Pues aunque se Ilegasen a olvidar, yo no te olvidaré... Porque, como una tierra hace germinar plantas... así el Señor Yahveh hace germinar la justicia... Por amor de Sión no he de callar, por amor de Jerusalén... hasta que salga como resplandor su justicia, y su salvación brille como antorcha.

\section{d) El recuerdo de las misericordias de Dios y la exigencia de conversión}

En delinitiva, el profeta hace una especie de meditación recordando las misericordias y bondades de Dios, sus acciones liberadoras por amor $y$ compasión. Este recuerdo va unido a la pelición de ayuda para que el pueblo cambic sus caminos.

Las misericordias de Yahveh quiero recordar, las alabanzas de Yahveh, por todo lo que nos ha premiado Yahveh, por la gran bondad para la casa de Israel, que luvo con nosotros en su misericordia, y por la abundancia de sus bondades... en todas sus angustias5. No fue un mensajero ni un ángel: él mismo en persona los liberó. Por su amor y su compasión él los rescato: los levantó en brazos ${ }^{6}$ y los llevó todos los dias desde siempre... ¿Por qué nos dejaste errar, Yahveh, fuera de tus caminos, endurecerse nuestros corazones lejos de iu temor? Vuélvete, por amor de tus siervos... (Is 63, 7.9.17).

4. También en el Antiguo Testamento aparece que la justicia va unida al amor. Este es la radicalización de la justicia.

5. El segundo Isaías comienza a hablar del Siervo de Yahveh, que cargará sobre él los sufrimientos del pueblo. Está afirmando así que Dios es tan solidario con la humanidad que sufre con ella. Así abre el camino para poder entender la actitud de entrega total de Jesús, hasta la muerte, por amor y solidaridad.

6. Este lenguaje es semejante al que ya hemos visto en Oseas. 


\section{La crisis postexilica: la época persa (500-333 a. C.)}

Tras el exilio, el retomo y la restauración también supusieron una crisis de fe en Dios. Fue un tiempo en que la comunidad judía se movió en medio de la pérdida de la propia identidad, la búsqueda de la misma, el peligro de caer en un fanatismo nacionalista, el intento de identificación propia a través de cosas externas y la poca esperanza en Dios. De hecho, la crisis más importante se produjo por el no reconocimiento de lo que hemos llamado el estilo de Dios, porque eso va contra la fe específica de Israel.

En esta situación, los grandes creyentes ayudaron a superar la crisis del pueblo. ¿Cómo lo hicieron? ¿Qué dijeron? Éste fue su mensaje.

Ante todo se preguntaban si Dios ha abandonado a su ciudad. Así habla Isaías 27, 11: "la ciudad fortificada que ha quedado solitaria... Cuando se seca su ramaje es quebrado en astillas: vienen mujeres y le prenden fuego. Por no ser éste un pueblo inteligente, por eso no le tiene piedad su Hacedor, su Plasmador no le olorga gracia".

Pero no es así. Dios ha enviado siempre mensajeros, como dicen los cronistas en 2 Crónicas 36,15 , en su resumen final, al afirmar que Dios "siempre tuvo compasión de su pueblo y de su casa". De lo que se trata es de que el pueblo vuelva su mirada hacia Dios y permita así que Dios le vuelva la mirada con compasión. Así lo afirma Malaquías en 1, 9, dirigiéndose especialmente a los sacerdotes, que en lugar de desempeñar su tarea de unir al pueblo con Dios lo van apartando: "Procuren complacerme y yo les compadeceré y les acogeré favorablemente".

Pero ¿cómo volver la mirada hacia Dios? Los grandes creyentes de aquel tiempo dan una serie de pautas.

a) Pedir la compasión de Dios. La respuesta del pueblo debe ser la de pedir con todas sus fuerzas la compasión y la esperanza. Así aparece en la oración del pueblo, en Isaías 33, 2: "Señor, compadécete de nosotros. Esperamos en ti. Sé cada mañana la fuerza de tu pueblo y sálvanos en la hora del peligro".

b) La conversión a Dios. En 2Crónicas 30, 9, cuando el rey Ezequías convoca para celebrar la pascua reformada, llama a la conversión, diciendo: "Porque si se vuelven a Yahveh, sus hermanos y sus hijos hallarán misericordia ante aquellos que los llevaron cautivos, y volverán a esta tierra, pues Yahveh su Dios es clemente y misericordioso, y no apartará de ustedes su rostro, si usledes se convierten a él".

Se pide, pues, la conversión para que Dios tenga compasión de ellos. Pero esta conversión se dice que debe ser una conversión del corazón, sincera y llena de confianza. Así aparece en Joel 2, 13: “Desgarren su corazón y no sus vestidos, vuelvan a Yahveh su Dios, porque él es clemente y compasivo, tardo a 
la cólera, rico en amor, y se ablanda ante la desgracia". La conversión, pues, encuentra la seguridad de un Dios que es compasivo.

c) La práctica de la justicia y de la misericordia. Para la reconsırucción del pueblo, Dios afirma que es necesario que "ustedes juzguen con justicia y tengan un trato amoroso y compasivo cada persona con su projimo" (Zac 7,9$)$.

d) Reconocer el estilo de actuar y de ser de Dios. Esta exigencia es la más importante por lo que toca al tema de este artículo. Se pide reconocer que Dios es amor y que actúa por amor. Este reconocimiento es puesto en boca de personajes como David, Salomón, Nehemías, Hiram, la reina de Saba, Jonás..., y también en plegarias como la de Salomón, Nehemías, los salmos y otras. He aquí algunos textos:

Y conoció David que Yahveh le había confirmado como rey de Israel, pues había ensalzado su realeza por amor a /srael su pueblo (1Cro I4, 2).

Oh Yahveh, por amor de tu siervo, y según tu corazón, has hecho todas estas cosas tan grandes, para manifestar todas estas grandezas (1Cro 17, 19).

David respondió a Gad: Estoy en gran angustia. Pero jcaiga yo en manos de Yahveh, que es grande su misericordia, y no caiga en manos de los hombres! (1Cro 2l, 13).

Salomón respondió a Dios: Tu tuviste gran amor a mi padre David, y a mí me has hecho rey en su lugar $(2 \mathrm{Cro} 1,8)$.

Y dije: Ah, Yahveh, Dios del cielo, tú, el Dios grande y temible, que guardas la alianza y el amor a los que te aman y observan tus mandamientos. (Neh 1,5 ).

Hiram, rey de Tiro, respondió en una carta que envió al rey Salomón: por el amor que tiene Yahveh a su pueblo te ha hecho rey sobre ellos $(2 \mathrm{Cro} 2,10)$.

¡Bendito sea Yahveh, tu Dios, que se ha complacido en ti, poniéndote sobre su trono como rey de Yahveh, tu Dios, por el amor que cu Dios tiene hacia lsrael para conservarle por siempre, y te ha puesto por rey sobre ellos para administrar derecho y justicia! (2Cro 9, 8).

Jonás también reconoce que lo que mueve la acción de Dios es, precisamente, la compasión, la benignidad, el amor. Es por esta razón por la que no quería ir a predicar a Nínive, ya que sabía que Dios, en último término, se arrepentiría del mal que le había enviado a anunciar. Así aparece en el siguiente texto:

Y oró a Yahveh diciendo: ¡Ah, Yahveh!, ¿no es esto lo que yo decía cuando estaba todavía en mi tierra? Fue por eso por lo que me apresuré a huir a Tarsis. Porque bien sabia yo que tú eres un Dios clemente y misericordioso, rardo a la cólera y rico en amor, que se arrepiente del mal (Jon 4,2). 
También en las grandes plegarias escritas en este tiempo del postexilio se parte siempre de este reconocimiento del modo de ser y actuar de Dios. He aquí algunos textos significativos:

[Salomón] dijo: Yahveh, Dios de Israel, no hay Dios como tú ni en el cielo ni en la tierra; tú que guardas la alianza y el amor a tus siervos que andan en tu presencia con todo su corazón... Atiende a la plegaria de tu siervo y a su petición, Yahveh, Dios mío, y escucha el clamor y la plegaria que tu siervo hace en tu presencia... Yahveh, Dios mío, no rechaces el rostro de tu Ungido; acuérdate de las misericordias otorgadas a David tu siervo. Entonces todos los hijos de Israel, viendo descender el fuego y la gloria de Yahveh sobre la Casa, se postraron rostro en tierra sobre el pavimento y adoraron y alabaron a Yahveh porque es bueno, porque es eterno su amor (2Cro 6, 14.19.42; 7, 3).

Esta celebración de la grandeza y del amor del Señor aparece continuamente en esta época, tal como se ve en textos como 1Crónicas 16, 34.41; 2Crónicas 5, 13; 7, 6; 20, 21; Esdras 3, 11.

También es significaliva la plegaria de Nehemías cuando le pide a Dios que tenga piedad de él, según su gran misericordia, respondiendo así a la piedad que Nehemías ha mostrado al servicio de Dios:

¡Acuérdate de mí por esto, Dios mío; no borres las obras de piedad que yo hice por la Casa de mi Dios y por sus servicios!... Ordené también a los levitas purificarse y venir a guardar las puertas, para santificar el sábado. ¡También por esto acuérdate de mí, Dios mío, y ten piedad de mi según tu gran misericordia! (Neh 13, 14.22).

Y en la gran plegaria de Nehemías, con ocasión de la liturgia penitencial pidiendo perdón por los matrimonios mixtos, encontramos las siguientes frases:

Hallaste su corazón fiel ante ti, con él hiciste alianza, para darle el país del cananeo, del hitita y del amorreo, del perizita, del jebuseo y del guirgasita, a él y a su posteridad. $Y$ has mantenido tu palabra, porque eres justo... Tú viste la aflicción de nuestros padres en Egipto, y escuchaste su clamor junto al mar de Suf... Tú, en tu inmensa ternura, no los abandonaste en el desierto: la columna de nube no se apartó de ellos, para guiarles de día por la ruta, ni la columna de fuego por la noche, para alumbrar ante ellos el camino por donde habían de marchar... Tú los entregaste en poder de sus enemigos que los oprimieron. Durante su opresión clamaban hacia ti, y tú los escuchabas desde el cielo; en tu inmensa ternura les mandabas salvadores que los libraron de las manos opresoras... Pero, apenas en paz, volvían a hacer el mal ante ti, y tú los dejabas en mano de sus enemigos que los oprimían... Ellos de nuevo gritaban hacia ti, y tú escuchabas desde el cielo: imuchas veces, por ternura, los salvaste! Así en tu inmensa ternura no los acabaste, 
no los abandonaste, porque eres tú Dios clemente y lleno de ternura... Ahora, pues, oh Dios nuestro, tú, Dios grande, poderoso y temible, que mantienes la alianza y el amor7, no menosprecies esta miseria que ha caido sobre nosotros, sobre nuestros reyes y príncipes, nuestros sacerdotes y profetas, sobre todo tu pueblo, desde los tiempos de los reyes de Asiria hasta el dia de hoy (Neh 9, 8.9.19.27.28.3I.32).

Nehemfas, pues, pide a Dios que siga actuando como siempre, compasivo, lleno de ternura, clemente...

No es necesario insistir aquí en el papel que juegan los salmos - la mayoria de ellos pueden ser considerados plegarias del postexilio- en la presentación de este estilo y modo de ser de Dios. Lo que sí es importante — para terminar- es recordar la convicción, también en el postexilio, de que Dios sí actuará según él es. Así animan los creyentes a la fe y a la esperanza del pueblo desencantado.

Por eso, así dice Yahveh: a Jerusalén me vuelvo con piedad: en ella será reedificada mi Casa —oráculo de Yahveh Sebaot-y cordel será tendido sobre Jerusalén (Zac 1, 16).

Así dice Yahveh: como cuando se encuentra mosto en el racimo y se dice: no lo eches a perder, porque es una bendición, así haré yo por amor de mis siervos, evitando destruirlos a todos (Is 65, 8).

Serán ellos para mí, dice Yahveh Sebaot, en el día que yo preparo, propiedad personal; y yo sere indulgente con ellos como es indulgente un padre con el hijo que le sirve (Mal 3, 17).

Yo seré para él un padre y él será para mi un hijo, y no apartaré de él mi amor, como le apané de aquel que fue antes de ti (1Cro 17, 13).

Y Yahveh se llenó de celo por su tierra, y tuvo piedad de su pueblo. Respondió Yahveh y dijo a su pueblo: he aquí que yo les envío grano, mosto y aceite virgen: se hartarán de ello, y no les entregaré más al oprobio de las naciones (Joel 2, 18-19).

\section{La crisis postexílica: la época helenista tolerante (333-200 a. C.)}

En esta época comienza la invasión del poder griego y de la cultura helenista, una cultura totalmente diferente a la cultura y a la fe hebreas. Se debe decir, sin embargo, que los primeros 125 años, desde el año 333 hasta el 200 a. C., mientras Judea dependía de los helenistas de Egipto, la relación entre éstos

7. Hasta ese momento de la oración aparece un reconocimiento de Dios en la historia; una historia en la que el pueblo ha tenido momentos de infidelidad, en los que Dios parecía haberse alejado. 
y los judíos fue relativamente pacífica. Los helenistas egipcios tenían bajo su poder al pueblo judío, pero lo respetaban en su fe y sus costumbres.

El peligro consistía en que poco a poco se fuesen introduciendo la fe y la cultura helenistas, muy atractivas por cierto. Eso hacía necesario hacer alrayentes la fe y la cultura judías, y, en cualquier caso, mantener la figura y el estilo de Dios. Era necesario, por tanto, presentar a los jóvenes judíos de una manera atractiva y modema la propia fe y cultura. Era necesario recordar al pueblo judío lo atractivo de la figura de Dios y del estilo que Dios había ido mostrando a lo largo de la historia. Veámoslo en algunos de los libros más típicos de esta época.

\subsection{Tobías}

El primer libro bíblico que lleva a cabo esta tarea es el de Tobías. Toda la historia de la familia de Tobit es un ejemplo de afirmación de aquello que es propio del pueblo judío, y sobre todo de la recuperación de la imagen de Dios, de aquello que distingue al Dios Yahveh de los otros dioses.

En la súplica de Sara a Dios por lodas las desgracias que ha sufrido (se invita así a que todo el pueblo haga lo mismo, en aquella época, ante la incertidumbre) aparece el nexo entre la invocación al "Dios de las misericordias" y la petición de que "mire con compasión":

Y en aquel momento, extendiendo las manos hacia la ventana, oró así: bendito seas tú, Dios de misericordias, y bendito sea tu Nombre por los siglos, y que todas tus obras te bendigan por siempre... Vuelvo ahora mi rostro y alzo mi ojos hacia ti... que no he mancillado mi nombre ni el nombre de mi padre en la tierra de mi cautividad. Soy la única hija de mi padre; no tiene otros hijos que le hereden, no tiene junto a sí ningún hermano ni pariente a quien me deba por mujer. Ya perdí siete maridos: ¿para qué quiero la vida? Si no te place, Señor, darme la muerte, ¡mírame con compasión! y no tenga yo que escuchar injurias (Tob 3, 11.12.15).

Y en la acción de gracias de Ragüel, una vez acabado el maleficio de Sara, se atribuye a la gran piedad y compasión de Dios:

Seas bendecido por haberme alegrado y no haber ocurrido el mal que temía, sino que has hecho con nosotros según tu gran piedad. Seas bendecido por tener compasión de dos hijos únicos. Ten, Señor, piedad de ellos y dales lu salvación, y haz que su vida transcurra en alegría y piedad (Tob 8, 16-17).

De nuevo, al recuperar la vista, Tobit agradece la gran piedad y compasión que Dios ha tenido con él:

Porque me había azotado, pero me tiene piedad y ahora veo a mi hijo Tobías. Tobías entró en casa lleno de gozo y bendiciendo a Dios con toda su voz; luego contó a su padre el éxito de su viaje, cómo traía el dinero y cómo se 
había casado con Sara, la hija de Raguiel, y que venía ella con él y eslaba ya a las puertas de Nínive... Tobit salió al encuentro de su nuera hasta las puertas de Nínjve, bendiciendo a Dios, lleno de gozo. Cuando los de Nínive le vieron caminar, avanzando con su antigua firmeza, sin necesidad de lazarillo, se maravillaron. Tobit proclamó delante de ellos que Dios se habia compadecido de él y le había abierto los ojos (Tob 11, 15-16).

En el cántico de acción de gracias de Tobil, Dios es invocado como quien castiga y tiene compasión, quien permite la muerte y arranca de ella, quien castiga las injusticias y tiene compasión y se compromete a reunir a los dispersos. Se hace un llamado a la conversión y a la justicia con la esperanza de que Dios actúe de nuevo y tenga misericordia. En este cántico aparece un nexo entre la acción de Dios, la compasión y la esperanza.

Porque él es quien castiga y tiene compasión; el que hace descender hasta el más profundo Hades de la tierra y el que hace subir de la gran Perdición, sin que haya nada que escape de su mano... Les ha castigado por sus injusticias, mas tiene compasión de todos ustedes y les juntará de nuevo de entre todas las gentes en que les ha dispersado. Si se vuelven a él de todo corazón y con toda el alma, para obrar en verdad en su presencia, se volverá a ustedes sin esconder su faz. Miren lo que ha hecho con ustedes y confiésenle en alta voz... ¡Vuelvan, pecadores! Practiquen la justicia en su presencia. ¡Quién sabe si les amará y les tendrá misericordia!... ¡Jenusalén, ciudad santa! Dios te castigó por las obras de tus hijos, pero tendró otra vez piedad de los hijos de los justos. Confiesa al Señor cumplidamente y alaba al Rey de los siglos para que de nuevo levante en ti con regocijo su tienda, y llene en ti de gozo a todos los cautivos y muestre en ti su amor a todo miserable... (Tob 13, 2.5.6.9.10).

Finalmente, en sus últimas palabras, Tobit le dice a su hijo que vuelva al lugar de origen de la familia (Media), ya que Dios se compadecerá de ellos por siempre. Se da, pues, un nexo entre futuro de felicidad y compasión de Dios.

Pero Dios tendrá una vez más compasión de ellos y los volverá a la tierra de Israel; construirán de nuevo la Casa, aunque no como la primera, hasla que se cumplan los tiempos; entonces volverán todos del destierro, edificarán una Jerusalén maravillosa y construirán en ella la Casa de Dios, como lo anunciaron los profetas de Israel (Tob 14,5).

\subsection{Jesús hijo de Sira}

Hay otro libro que se ubica en este primer momento de la dependencia de los judios de los helenistas egipcios. Se trata del libro Jesús hijo de Sira. En él se hace una exhortación al joven judío, proponiéndole la verdadera imagen de Dios para que actúe de acuerdo con su estilo. Son sentencias sapienciales, recogidas

Digitalizado por Biblioteca "P. Florentino Idoate, S.J."

Universidad Centroamericana José Simeón Cañas 
en este tiempo para conseguir que el joven judío se deje llevar por la sabiduría de su Dios y le respete. Algunos de sus textos definen el estilo de Dios y llaman a no alejarse de él:

Los que temen al Señor, aguarden su misericordia, y no se desvien para no caer... Los que temen al Señor, esperen bienes, contento eterno y misericordia... Que el Señor es compasivo y misericordioso, perdona los pecados y salva en la hora de la tribulación... Caeremos en manos del Señor y no en manos de los hombres, pues como es su grandeza, tal su misericordia (Sir 2, 7.9.11.18).

Por otra parte, se afirma que la compasión de Dios no hay que entenderla como una especie de seguro contra su justa cólera:

No digas: su compasión es grande, él me perdonará la multitud de mis pecados. Porque en él hay misericordia, pero también hay cólera, y en los pecadores se desahoga su furor... Aunque fuera uno solo el de dura cerviz, sería asombroso que quedara impune. Pues misericordia e ira están con El, tan poderoso en perdón como pródigo en ira... Tan grande como su misericordia es su severidad, según sus obras juzga al hombre (Sir 5,$6 ; 16,11-12$ ).

Se dice también que quien se convierte goza de la misericordia y del perdón de Dios:

¿Qué grande es la misericordia del Señor, y su perdón para los que a él se convierten! (Sir 17, 29).

Se insiste en el amor inmenso y paciente de Dios:

El poder de su majestad, ¿quién lo calculará?, ¿quién pretenderá contar sus misericordias? (Sir 18,5). Por eso el Señor es paciente con ellos, y derrama sobre ellos su misericordia... La misericordia del hombre sólo alcanza a su prójimo, la misericordia del Señor abarca a todo el mundo. El reprende, adoctrina y enseña, y hace volver, como un pastor, a su rebaño. Tiene piedad de los que acogen la instrucción, y de los que se afanan por sus juicios (Sir 18, 11.13.14).

Se denuncia la incoherencia de quien pide misericordia y perdón de Dios y es, en cambio, incapaz de ser misericordioso y perdonar:

De un hombre como él piedad no tiene, iy pide perdón por sus propios pecados! El, que sólo es carne, guarda rencor, ¿quién obtendrá el perdón de sus pecados? (Sir $28,4.5$ ).

Se insiste en que ser como Dios quiere decir ser misericordioso; y en esto, la limosna solidaria es una señal concreta:

Quien hace misericordia, presta al projimo, quien le apoya con su mano, guarda los mandamientos (Sir 29, 1).

Digitalizado por Biblioteca "P. Florentino Idoate, S.J."

Universidad Centroamericana José Simeón Cañas 
Se da la razón, que no es otra que Dios escucha siempre el clamor del pobre:

Las lágrimas de la viuda, ¿no bajan por su mejilla, y su clamor contra el que las provocó?... Y el Señor no se tardará, ni tendrá con éstos más paciencia... Hasta no haber hecho justicia a su pueblo, y haberles dado contento con su misericordia (Sir 35, 15.19.23).

Se le pide piedad a Dios:

Ten piedad de nosotros, Dios, dueño de todas las cosas, mira y siembra tu temor sobre todas las naciones... Ten piedad, Señor, del pueblo llamado con tu nombre, de Israel, a quien igualaste con el primogénito... Ten compasión de tu santa ciudad, de Jerusalén, lugar de tu reposo (Sir 36, 1.11.12).

Se constata que el hecho de que Dios haya dejado un resto es ya un signo de su piedad:

Pero el Señor no renuncia jamás a su misericordia, no deja que se pierdan sus palabras ni que se borre la descendencia de su elegido, el linaje de quien le amó no extirpa. Por eso dio a Jacob un resto y un brote a David salido de él (Sir 47, 22). Invocaron al Señor misericordioso, tendiendo sus manos hacia él. Y el Santo, desde el cielo, los escuchó al instante, y los rescató por mano de Isaías (Sir 48, 20).

Se pide en la exhortación final que bendigan a Dios:

$Y$ ahora bendigan al Dios del universo, el que por todas partes hace grandes cosas, el que exaltó nuestros días desde el seno matemo, que nos trata según su misericordia. Que nos dé contento de corazón, y que haya paz en nuestros días en Israel por los siglos de los siglos. Que su misericordia sea fiel con nosotros y en nuestros días nos rescale (Sir 50, 22-24).

$\mathrm{Y}$ acaba con esta plegaria:

Pues protector y auxilio has sido para mí, y has rescatado mi cuerpo de la perdición, del lazo de la lengua insidiosa, de los labios que urden mentira; frente a mis adversarios has sido auxilio y me has rescatado, según la abundancia de tu misericordia y la gloria de tu nombre, de las dentelladas de los dispuestos a devorarme, de la mano de los que buscan mi alma, de las muchas tribulaciones que he sufrido, del ahogo del fuego que me envolvía, de entre el fuego que yo no había encendido, de la hondura de las entrañas del seol, de la lengua impura, de la palabra mentirosa - calumnia de lengua injusta ante el rey. Cerca de la muerte estaba mi alma, mi vida estaba junto al seol, abajo. Por lodas partes me asediaban y no había quien auxiliara, volví los ojos a un apoyo humano y no había ninguno. Entonces me acordé de tu misericordia, Señor, y de tu actuación desde la eternidad, que tú levantas a los que en li esperan, y los salvas de la mano de los enemigos (Sir $51,2-8$ ). 
En sus últimas palabras, Jesús hijo de Sira exhorta a alegrarse en la misericordia de Dios: "Que su alma se recree en la misericordia del Señor, no se avergüencen de su alabanza" (Sir 51, 29).

\section{El helenismo agresivo y violento, o la resistencia (200-150 a C.)}

Un segundo momento del helenismo fue la invasión violenta, especialmente bajo Antíoco IV. Fue un tiempo de resistencia activa y pasiva, liempo de guerrilleros y mártires, tiempo trágico. En él, el recuerdo de historias pasadas y presentes, en que Dios se ha mostrado como es, anima a resistir. Daniel y el segundo libro de los Macabeos son los libros que lo muestran con mucha insistencia.

\subsection{Daniel}

En el libro de Daniel se recuerda la misericordia de Dios de diversas maneras. Daniel pide que oren a Dios para que el rey no lo mate, si es que no sabe interpretar el sueño. "Daniel se fue a casa y habló con los suyos, invitándolos a implorar la misericordia del Dios del Cielo, acerca de este misterio, a fin de que no se diese muerte a Daniel y a sus compañeros con el resto de los sabios de Babilonia" (Dan 2, 18).

Condenados a morir en el fuego tres jóvenes junto con Daniel, éste ruega a Dios para que no retire su misericordia. " $\mathrm{OOh}$, no nos abandones para siempre - por amor de tu nombre-, no repudies tu alianza, no nos retires $t u$ misericordia, por Abraham tu amado, por Isaac iu siervo, por Israel tu santo... trátanos conforme a tu bondad y según la abundancia de lu misericordia" (Dan 3, 34.35.42).

Salvados del horno, dan gracias a Dios, repitiendo las mismas palabras: "Den gracias al Señor, porque es bueno, porque es eterna su misericordia. Todos los que veneran al Señor, bendigan al Dios de los dioses, cántenle, denle gracias, porque es eterna su misericordia" (Dan 3, 89-90).

Daniel descubre el sueño de Nabucodonosor y le aconseja que rompa sus pecados con obras de misericordia para que Dios esté con él. Le dice: "Por eso, oh rey, acepta mi consejo: rompe tus pecados con obras de justicia y tus iniquidades con misericordia para con los pobres, para que tu ventura sea larga" (Dan 4, 24).

Y cuando Daniel pide a Dios la venida de la nueva Jerusalén, lo define como quien ama y en cuya misericordia nos podemos amparar.

Derramé, mi oración a Yahveh mi Dios, y le hice esta confesión: ¡Ah, señor, Dios grande y temible, que guardas la Alianza y el amor a los que te aman y observan tus mandamientos. A ti, Señor, la justicia, a nosotros la vergüenza en el rostro, como sucede en este día, a nosotros, a los hombres de Judá, a los Digitalizado por Biblioteca "P. Florentino Idoate, S.J."

Universidad Centroamericana José Simeón Cañas 
habitantes de Jerusalén y a Israel entero, próximos y lejanos, en todos los países donde tú los dispersaste a causa de las infidelidades que cometieron contra ti... Al Señor Dios nuestro, la piedad y el perdón, porque nos hemos rebelado contra él... Inclina, Dios mío, tu oído y escucha. Abre tus ojos y mira nuestras ruinas y la ciudad sobre la cual se invoca tu nombre... No, no nos apoyamos en nuestras obras justas para derramar ante ti nuestras súplicas, sino en tus grandes misericordias (Dan 9, 4.7.9.18).

En liempos de persecución, pues, Daniel vuelve de nuevo la mirada hacia el Dios lleno de misericordia y, en nombre de esta misericordia, se atreve a pedirle salvación.

\subsection{Segundo libro de los Macabeos}

El otro libro escrito en medio de la persecución y la violencia es el segundo libro de los Macabeos. Aparece en él una imagen de Dios que lleva a la resistencia armada y al martirio.

En la carta de los judios de Jerusalén a los de Egipto, aquéllos recuerdan a éstos que cuando Nehemías reunió al pueblo para la fiesta de las Tiendas, la oración comenzaba así: "Señor, Señor Dios, creador de todo, temible y fuerte, justo y misericordioso, tú, rey único y bueno..." (2Mac 1,14$)$. Y en medio de la persecución se interrumpe el relato y se recuerda a Dios como el que "nunca retira de nosotros su misericordia: cuando corrige con la desgracia, no está abandonando a su propio pueblo" (2Mac 6, 16).

En el relato del martirio de los siete hermanos y de la madre se vuelve a recordar cómo es Dios.

Pues asi el Creador del mundo, el que modeló al hombre en su nacimiento y proyectó el origen de todas las cosas, les devolverá el espíritu y la vida con misericordia, porque ahora no miran por ustedes mismos a causa de sus leyes... No temas a este verdugo, antes bien, mostrándote digno de lus hermanos, acepla la muerte, para que vuelva yo a encontrarte con lus hermanos en la misericordia (2Mac 7, 23.29).

Antes de ir al combate, Judas y los otros guerreros oran al Señor con estas palabras:

Rogaban al Señor que mirase por aquel pueblo que lodos conculcaban; que tuviese piedad del santuario profanado por los hombres impios; que se compadeciese de la ciudad destruida y a punto de ser arrasada, y que escuchase las voces de la sangre que clamaba a él; que se acordase de la inicua matanza de niños inocentes y de las blasfemias proferidas contra su nombre, y que mostrase su odio al mal. Macabeo, con su tropa organizada, fue ya invencible para los gentiles, al haberse cambiado en misericordia la cólera del Señor... Una vez que hubieron amontonado las armas y recogido Digitalizado por Biblioteca "P. Florentino Idoate, S.J."

Universidad Centroamericana José Simeón Cañas 
los despojos de los enemigos, comenzaron la celebración del sábado, desbordándose en bendiciones y alabanzas al Señor que en aquel día les había salvado, estableciendo el comienzo de su misericordia... Hecho esto [repartido el botín], en rogativa pública rogaron al Señor misericordioso que se reconciliara del todo con sus siervos (2Mac 8, 2-5.27.29).

Cuando Antíoco IV cayó gravemente enfermo, prometió muchas cosas a Dios, pero el relator nos dice que "aquel malvado rogaba al Soberano de quien ya no alcanzaria misericordia, prometiendo..." (2Mac 9, 13), y por tanto, su fin era seguro.

En medio de la campaña de Lysias, el Macabeo y los suyos bendicen al Dios misericordioso y avanzan porque se sienten fuertes. "Todos a una bendijeron entonces a Dios misericordioso y sintieron enardecerse sus ánimos, dispuestos a atravesar no sólo a hombres, sino aun a las fieras más salvajes y murallas de hierro. Avanzaban equipados, con el aliado enviado del Cielo, porque el Señor se había compadecido de ellos" (2Mac 11, 9-10).

Cuando Antíoco IV los quería privar de su ley y de todo lo más propio de ellos, Judas pidió al pueblo que invocase noche día al Señor y "una vez que todos juntos cumplieron la orden y suplicaron al Señor misericurdioso con lamentaciones y ayunos y postraciones durante tres días seguidos, Judas los animó y les mandó que estuvieran preparados" (2Mac 13,12$)$. El éxilo acompañó a Judas y a los suyos.

\section{La época de la influencia romana (150-0 a. C.)}

Existe, finalmente, un tercer momento helenista —más sutil-, que es el de la influencia romana. En esa época se está perdiendo el entusiasmo, pero el primer libro de los Macabeos, Judit, Baruc y, finalmente, Sabiduría ayudarán a mantener la confianza en Dios y su estilo. Favorecerán, así, el crecimiento del entusiasmo del pueblo.

\subsection{Primer libro de los Macabeos}

En este libro encontramos un primer texto en el que Matatías, el organizador de la resistencia macabea contra los helenistas, recuerda a todos los suyos la historia de los creyentes y cómo éstos siempre superaron las pruebas y los obstáculos: "David, por su piedad, heredó un trono real para siempre" (1Mac 2, 57). Y hablando del ejércilo helenista (y romano) dice:

Ellos vienen contra nosotros rebosando insolencia e impiedad con intención de destruimos a nosotros, a nuestras mujeres y a nuestros hijos, y hacerse con nuestros despojos; nosotros, en cambio, combatimos por nuestras vidas y nuestras leyes; El les quebrantará ante nosotros; no les teman (1Mac 3, 2022). 
También la asamblea es convocada para pedir piedad y misericordia ante el combate. Se dice que "se convocó la asamblea para prepararse a la guerra, hacer oración y pedir piedad y misericordia" (1Mac 3,44). De modo semejante se exhorta a orar diciendo: "Clamemos ahora al Cielo, a ver si nos tiene piedad, recuerda la alianza de nuestros padres y quebranta hoy este ejército ante nosotros" (1Mac 4, 10). Por esto cuando vuelven del combate van cantando: "Porque es bueno, porque es eterno su amor" (1Mac 4, 24).

Finalmente, Simón, ya anciano, dice a sus hijos Judas y Juan, que tienen capacidad para tomar su lugar y el de su tío, en la resistencia contra los invasores:

Pero ahora ya estoy viejo mientras que ustedes, por la misericordia del Cielo, están en buena edad. Ocupen, pues, mi puesto y el de mi hermano, salgan a combatir por nuestra nación y que el auxilio del Cielo sea con ustedes $(1 \mathrm{Mac} 16,3)$.

\section{Judit}

De esta misma época es el libro de Judil, que pretende generar enlusiasmo entre el pueblo, narrando historias del pasado. Nama así la guerra de Holofemes, jefe del ejército de Nabucodonosor, en la que la plegaria y la fe en un Dios misericordioso dieron ánimos al pueblo de Dios. "Señor, Dios del cielo, mira su soberbia, compadécete de la humillación de nuestra raza y mira con piedad el rostro de los que le están consagrados" (Jud 6, 19).

En el mismo contexto, cuanto más fuerte se va haciendo el asedio y el pueblo desconfía seriamente de Dios, Ozías les dice: "Tengan confianza, hermanos; resistamos aún cinco días, y en este tiempo el Señor Dios nuestro volverá su compasión hacia nosotros, porque no nos ha de abandonar por siempre" (Jud 7, 30).

Por último, tras la victoria de Judit sobre Holofernes, dice la heroína a sus compatriotas, al entrar en Betulia: "¡Alaben a Dios, alábenle! ¡Alaben a Dios, que no ha apartado su misericordia de la casa de Israel, sino que esta noche ha destrozado a nuestros enemigos por mi mano" (Jud 13, 14).

\subsection{Baruc}

Un tercer libro, escrito, al menos en algunas de sus partes, en el contexto del comienzo del dominio romano, es el de Baruc.

En la llamada "oración de los deportados" se dice: "No apoyados en las obras justas de nuestros padres y de nuestros reyes derramamos nuestra súplica de piedad ante lu rostro, oh Señor Dios nuestro... Sin embargo has obrado con nosotros, Señor Dios nuestro, según toda tu indulgencia y tu gran misericordia... 
Escucha, Señor, ten piedad, porque hemos pecado ante ti" (Bar 2, 19.27; 3, 2).

$Y$ en el contexto de las quejas y esperanzas mesiánicas, Jenusalén y sus habitantes comparten la esperanza: "Yo [Jerusalén] espero del Eterno la salvación de ustedes, del Santo me ha venido la alegría, por la misericordia que llegará pronto a ustedes de parte del Eterno, su Salvador... Porque Dios guiará a Israel con alegrfa a la luz de su gloria, con la misericordia y la justicia que vienen de éf' (Bar 4, 22; 5, 9a).

\subsection{Carta de Jeremías}

Finalmente, en aquellos momentos de peligro de dejarse llevar por los dioses de Grecia y Roma, en la llamada Carta de Jeremías contra la idolatría (que se halla en Baruc 6, 35-39) se ridiculiza a tales dioses

Jamás libran a un hombre de la muerte, ni arrancan al débil de las manos del poderoso. No pueden devolver la vista al ciego, ni liberar al hombre que se halla en necesidad. No tienen piedad de la viuda ni hacen bien al huérlano. A los peñascos sacados del monte se parecen esos maderos recubiertos de oro y plata, y sus servidores quedan en vergüenza. ¿Cómo, pues, se puede creer o afirmar que son dioses?

\subsection{Sebiduría}

El último libro del Antiguo Testamento, el libro de la Sabiduría, se escribe también en el difícil momento de la invasión romana, cuando los romanos someten cada vez más a los judíos, los quieren convertir y cambiarlos totalmente para hacerlos fieles servidores del imperio. En ese contexto, el libro de la Sabiduría plantea la tesis de que la auténtica sabiduría del pueblo judío es lo que lo hará feliz, que Dios ha tenido siempre paciencia con los opresores, pero que, en último término, los justos oprimidos alcanzarán el triunfo. Esto es lo que el libro dice de Dios.

En medio de la persecución ocasionada por intentar ser un pueblo fiel y justo, en los primeros cinco capítulos del libro se insiste en la victoria final de los justos, a pesar de las apariencias. Esto siempre es obra del amor y de la misericordia de Dios. Y es algo que sólo pueden entender los sabios.

Los que en él confían entenderán la verdad y los que son fieles permanecerán junto a él en el amor, porque la gracia y la misericordia son para sus santos y su visita para sus elegidos... que la gracia y la misericordia son para sus elegidos y su visita para sus santos (Sab 3, 9; 4, 15).

Por esto, en la segunda parte, en los capítulos 6 a 9, se hace el elogio de la sabiduría: la sabiduría de sentirse pequeño, de no querer ser poderoso y de estar convencido de que "al pequeño, por piedad, se le perdona, pero los poderosos serán poderosamente examinados" (Sab 6, 6).

Digitalizado por Biblioteca "P. Florentino Idoate, S.J."

Universidad Centroamericana José Simeón Cañas 
A esta sabidurla se accede de la siguiente manera: "su comienzo es el deseo más verdadero de instrucción, la preocupación por la instrucción es el amor, el amor es la observancia de sus leyes, la atención a las leyes es la garantía de la incortuptibilidad" (Sab 6, 17.18).

Este camino, tan importante, no es fácil, sino que es don de Dios y por esto es necesario pedirlo en nombre de lo más sagrado, que es su misericordia. "Pero, comprendiendo que no podría poseer la Sabiduría si Dios no me la daba y ya era un fruto de la prudencia saber de quién procedía esta gracia- recurtí al Señor y le pedí, y dije con lodo mi corazón: Dios de los padres, Señor de lo misericordia, que hiciste el universo con tu palabra" (Sab 8, 21; 9, 1).

Todos deben pedir esta sabiduría, que les ayudará a vivir en medio de las dificultades causadas por la dominación romana, tal como ha ocurrido a lo largo de la historia. Por esto, la tercera parte del libro está dedicada a recorrerla para ver cómo la sabiduría ha acompañado misericordiosamente al pueblo en los momentos más difíciles. Son ejemplos que el pueblo debe tener delante, en el liempo de la dominación romana.

Así habla de Abraham: "En la confusión que siguió a la común perversión de las naciones, ella conoció al justo, le conservo irreprochable ante Dios y le mantuvo firme contra el entrañable amor a su hijo" (Sab 10, 5).

De Jacob: "Le preservó de sus enemigos y le protegió de los que le tendían asechanzas; y le concedió la palma en un duro combale para enseñarle que la piedad contra todo prevalece" (Sab 10, 12).

De los israelitas y los egipcios: "Pues cuando sufrieron su prueba -si bien con misericordia corregidos- conocieron cómo los impíos, juzgados con cólera, eran torturados" (Sab 11, 9). Te compadeces de todos porque todo lo puedes y disimulas los pecados de los hombres para que se arrepientan. Amas a todos los seres y nada de lo que hiciste aborreces, pues, si algo odiases, no lo habrías hecho (Sab II, 23.24).

De los cananeos: "Así pues, para aleccionarnos, a nuestros enemigos los flagelas con moderación, para que, al juzgar, tengamos en cuenta $t u$ bondad y, al ser juzgados, esperemos tu misericordia" (Sab 12, 22).

De Israel: "Mas tú, Dios nuestro, eres bueno y verdadero, paciente y con misericordia gobiernas el universo" (Sab 15, 1).

De Israel en el desierto: "A tus hijos, en cambio, ni dientes de serpientes venenosas los vencieron, pues vino tu misericordia en su socorro y los sanó" (Sab 16, 10).

De Israel en el mar Rojo: "Pero sobre los impíos descargó hasta el fin una ira sin misericordia, pues Dios sabía de antemano lo que iban a tramar" (Sab 19, 1). 
Durante la crisis helenista y romana, por tanto, a Israel no se le dio otra solución que volver a redescubrir cómo es Dios y qué estilo misericordioso tiene con el pueblo.

\section{Conclusión}

No quiero acabar este recorrido por el Antiguo Testamento sin salir al paso de una objeción que para mucha gente puede ser piedra de escándalo. A lo largo de todo el recorrido hecho por la historia del pueblo de Israel, puede haber quedado la impresión de que la misericordia de Dios es muy parcial y selectiva, que Dios ha obrado salvando a su pueblo, pero a base de mostrar una gran agresividad hacia los otros pueblos. ¿Qué decir de esto?

Lo primero que hay que afirmar es que la misericordia de Dios se parcializà a favor de Israel no porque sea mejor o tenga más mérito que otros pueblos, sino porque es un pueblo pequeño, maltratado, miserable. Además hay que añadir que en varias ocasiones aparece también, en los textos veterotestamelarios, la afirmación de que Dios no sólo ha elegido a Israel para salvarlo, sino que también se ha preocupado por los egipcios, los cananeos, los filisteos, los arameos y por todos los pueblos (cfr. Am 9, 7; Is 19, 22-25; 45, 14; 49, 6; Za 14, 16; Sa 11, 21-26). O dicho de otro modo, a lo largo de la historia de Israel, Dios se ha ido manifestando con una misericordia cada vez más universal y así lo fueron comprendiendo paulatinamente los creyentes. Es significativa en este sentido la lección del libro de Jonás. En éste, Jonás, típico representante de la línea particularista judía, no quiere obedecer a Dios cuando lo envía a Nínive, la capital de Asiria, porque, sabiendo que Dios "es clemente y misericordioso, tardo a la cólera y rico en amor", se puede anrepentir de hacerle mal a Nínive; y esto es insoportable para Jonás. Al final, Dios lo hace caer en la cuenta de que no sería Dios si no tuviera "lástirna de Nínive, la gran ciudad, en la que hay más de ciento veinte mil personas", que no saben qué tienen que hacer (cfr. Jon 4, 2.11).

No puedo ahora extenderme en este tema de la universalización de la misericordia, ya que podría ser objelo de otro extenso estudio. Paso, pues, a mi conclusión.

A lo largo de este artículo, hemos recorrido la compleja historia del pueblo de Dios. Hemos visto que en ésta hubo momentos mejores y peores, momentos de gran descubrimiento del estilo de actuar de Dios y otros de oscurecimiento. En todo caso, lo que sí ha ido quedando claro es que en todas las circunstancias en las que se fue encontrando el pueblo, siempre surgieron creyentes que ayudaron al pueblo de Dios a tener como punto de referencia para seguir adelante la experiencia de un Dios que estaba presente en su historia y que lo estaba con el estilo de siempre: atento al clamor del pueblo pobre y oprimido, liberador, justo, compasivo, defensor del huérfano y la viuda, dado al perdón, amoroso, tierno y misericordioso. 
Esta presencia de Dios y este estilo suyo se han hecho especialmente visibles y claros en la historia con la aparición en la humanidad de Jesús de Nazareth, la máxima muestra de un Dios con entrañas de misericordia. El anunciar con la propia palabra y el transmitir con la propia vida dicha presencia y estilo de Dios en la historia y en la vida, es el gran reto para los creyentes y seguidores de este tal Jesús, el Cristo. 